\title{
Analysis of reasons for cost and time overrun in Indian megaprojects
}

\author{
Jay Mevada ${ }^{1}$, and Ganesh Devkar ${ }^{2 *}$ \\ ${ }^{1}$ Post graduate student in Construction Engineering and Management, Faculty of Technology, CEPT \\ University, 380009 Ahmedabad, India \\ ${ }^{2}$ Associate Professor, Faculty of Technology, CEPT University, 380009 Ahmedabad, India
}

\begin{abstract}
Megaprojects are becoming increasingly common in developing countries. In India, the need for and trend of rapid infrastructure development has resulted in design and implementation of projects of large scope and size, in terms of complexity and costs. As a result, megaprojects are being implemented in almost all infrastructure sectors in the country. The implementation of a megaproject attracts a lot of attention among the policy makers and researchers owing to their enormous economic, social and environmental impacts. The performance of megaprojects in terms of two key parameters - cost and time - is closely monitored by the Government of India, and this has resulted in the publication a set of reports to disclose information on project progress. Althoughquantitative analyses of the information available in these reports have been performed by the researchers, very few qualitative analysis reports are available. In this context, a qualitative research study has been undertaken in this work, to analyse the reasons for time and cost overrun in megaprojects. The analysis furthers the knowledge on megaprojects implementation by providing inference on not only key reasons for time and cost overruns but also factors and trajectories leading to the manifestation of a particular cause. The analysis indicates that delay in land acquisition, capability of contractors and contractual complexity were the major causes of time and cost overruns and these issues traverse through different layers - policy, institutional and project associated with megaprojects. The study findings are useful to policy makers to design interventions at these three layers for addressing the cause of time and cost overruns, and ensuring effective implementation of megaprojects.
\end{abstract}

\section{Introduction}

Infrastructure projects form the core of policy making in any country. Although priorities across different sectors, modes of financing and contractual mechanisms differ from country to country, there is an underlying and undeniable trend that has been spreading across the world -the emergence of "mega" infrastructure projects. Flyvbjerg (2015) mentions a figure of US\$6 to US\$9 trillion annually or $8 \%$ of the total global gross

"ganesh.devkar@,cept.ac.in 
domestic product (GDP)towards megaproject spending [7]. These megaprojects span different sectors including transport, airport, oil and gas, road and so on. The megaproject phenomenon is expanding into sectors such as health, education and information technology.

The conceptualization of megaprojects stretches beyond the human bounded rationality owing to far reaching economic, social, technical and policy implications resulting from them. However, the human mind perceives the concept - "mega" in terms of cost, scale, time, complexity, and money. All these concepts create a challenge to megaproject managers, owing to poor track record and history of megaprojects [3].

There are numerous policy documents, audit reports, research reports and practice notes that describe and dissect the implementation of megaprojects. These documents typically focus on two interrelated spectra,viz. the institutional mechanisms that can be created to manage the complexity, risks, finance, stakeholders and uncertainties associated with megaprojects, and the effect of these mechanisms on performance parameters like time, cost, quality, and safety. Among these performance parameters, time and cost are two key parameters that are closely monitored by the clients/ implementing agencies.

The rationale behind monitoring has been huge cost and time overruns experienced in megaprojects world over. Most megaprojects are implemented using public money. Owing to legitimacy, transparency and accountability associated with the use of these funds, the implementing agencies/audit agencies/monitoring agencies have the obligation of informing the general public about the performance of these projects. These information disclosures have been used by researchers as secondary data in a case study of megaprojects as well as archival data analysis [12].

In India, megaprojects are now increasingly being implemented and the quantum of investments in mega projects in recent years has been impressive. The Ministry of Statistics and Project Implementation (MoSPI)has been monitoring the implementation of megaprojects funded by the Central government. It periodically publishes reports providing information on the status of megaprojects on the parameters of time and cost, and brief information on reasons for overruns, if any. A literature review of Indian megaproject shows that the performance of these projects has been investigated with the case study analysis method[26,33]. However, there are have not been any qualitative analysis of performance reports published by MoSPI. There are two studies that have been carried out by archival analysis; one of them does not distinguish megaprojects as a part of analysis while the other focuses on all types of projects executed with PPP mechanism, in the road sector [11]. This research study addresses this gap by conducting qualitative analysis of data published by the MoSPI pertaining to megaprojects. International literature on megaprojects includes studies using qualitative research strategies like a case study, interviews, and grounded theory[5]. However, there exists no study as yet, that has used qualitative analysis of archival data. In this context, a research study is undertaken to conduct qualitative analysis of performance reports on Indian megaprojects.

\section{Megaprojects: Indian scenario}

The infrastructure development has been accorded the top most priority status by the Indian government in the post liberalization era. This has resulted inmassive allocation of resources towards infrastructure development and "megaproject" has become a popular project delivery mechanism to channelize these resources for economic and social good. The Indian infrastructure sector is divided into three levels: central, state and local. Although there is a wide variety of grey literature like online magazines, newspapers, online websites and blogs that discuss different facets of megaprojects, there are no sources of precise information and there is a paucity of databases on megaprojects covering state 
and local level megaprojects. The megaprojects falling under the purview of the Central government are monitored by the "Infrastructure and Project Monitoring Division" of "Programme Implementation Wing" of MoSPI, and this division deals with projects that cost US\$22.54 million or more, in terms of the parameters of time and cost overrun since inception of the project.

Based on cost, projects are categorized as two types: 1) major projects are those that cost US\$ 22.54 million and above but below US\$150.34 million and 2) megaprojects are those that cost US\$ 150.34 million and above. The website of MoSPI contains precise information about the rationale for and date of categorization of various megaprojects. It can be seen that the monitoring of megaprojects commenced in May 2009 with publication of the $1^{\text {st }}$ Report on Megaprojects in June 2009. The monthly or flash reports on megaprojects are available in the MoSPI portal; the one on January 2012 constitutes the $43^{\text {rd }}$ Report on Megaprojects. Although, the $1^{\text {st }}$ Megaproject flash report was published in June 2009, the subsequent reports from May 2009 to December 2011 are not available in the database of MoSPI for accurate trend analysis of the number of megaprojects. The trend can however be inferred from the earliest available report - January 2012. The frequency of reports seen in the portal shows the importance afforded by the Central Government to "megaprojects" as an emerging project delivery mechanism and its close monitoring.

Figure 1 shows that in the year 2012, the number of megaprojects increased by 1.6 times from June 2009, i.e. 179 megaprojects (January 2012)compared to 112 megaprojects in June 2009. From January 2012 to September 2016, the number of megaprojects has increased 1.8 folds, i.e. from 179 (Jan 2012 to Sep 2016) to 337.

The academic literature on Indian megaprojects is very limited, although, the global research community, as well as Indian researchers, have initiated steps towards "megaprojects" research in recent years. Most of the research studies focus on urban megaprojects covering sectors such as metro, river front developments, and urban investments corridor. Siemiatycki analyzed the physical and societal implications of metro project in Delhi and concluded that the project failed to meet the transportation needs of the city [14]. The Information Technology (IT) corridor in Chennai,a prominent urban megaproject, was examined by Vijayabaskar \& Babu for understanding employment creation, mobility patterns and quality of urban development [10]. Follmann conducted case analysis of two large scale river front development projects namely the Akshardham Temple Complex and the Commonwealth Games Village, and contrasted them with the slum demolitions [15]. The pressures created by megaprojects on land and environment have been discussed in a couple of papers. Raghuram stressed on technology adoption for bringing transparency and fast tracking the process of environmental impact assessment and land acquisition [26]. Pomeranz, Bandoyadhay and Perveen assessed the mega watershed projects in the Himalayas, India and river-interlinking project from the viewpoint of environmental politics and efficient use of water resources respectively [13].

Alongside the academic literature, there is ever-growing information on megaprojects in secondary data sources like newspapers, trade magazines, online construction and infrastructure industry portals, online discussion forums and social media. This discourse broadly focuses on following: 1) megaprojects investments and scope of megaprojects, 2) funding, governance and reasons behind megaprojects, 3) large scale displacements of people caused by megaprojects, 4) policy and institutional hurdles in ultra-mega power plants. Some of the megaprojects that are often referred in these platforms are BandraWorli Sea Link, Mumbai Metro Rail, Delhi Metro Rail, Ahmedabad Metro Rail, Gujarat International Finance-Tec City, Delhi-Mumbai Infrastructure Corridor and Navi Mumbai International Airport. 
The academic and practitioner literature on megaprojects in India often whirls around the important issue of overruns in the areas of time and cost. This is not surprising, considering the global evidence on megaprojects indicating huge time and cost overruns.

MoSPIclosely monitors two parameters, i.e. cost overrun and time overrun with Indian megaprojects. Figure 1 shows the increase in number of megaprojects over the years as well as delays and cost overruns in megaprojects.

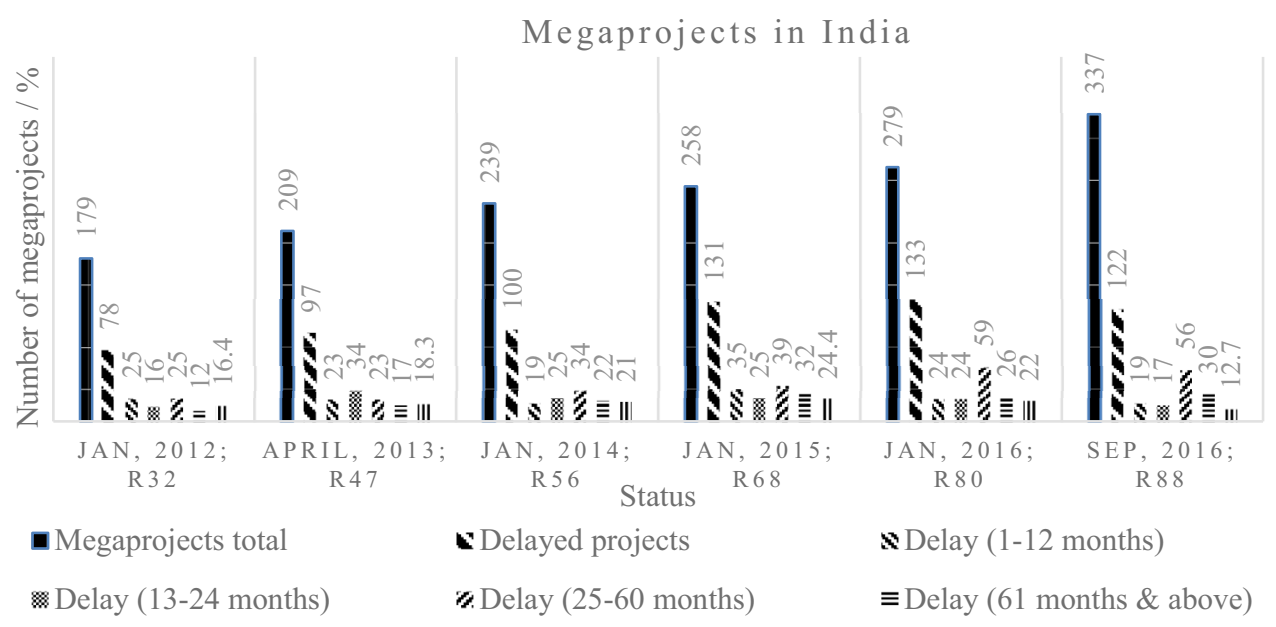

IIII Overall Cost overrun \%

Figure 1. Megaprojects trend in India

\section{Megaprojects: Complexity and Overrun}

Complexity is one of distinguishing feature of megaprojects, megaproject managers and implementing agencies have been facing challenges in managing this complexity. This naturally leads to a call for focus on complexity management among academic and practitioner community in the domain of megaprojects. Hu Yi performed bibliographic analysis of construction engineering and management research to understand the status and the trends in megaproject research [5]. The analysis indicated a move towards construction megaproject management to complex project management. There is variation in the conceptualization of "complexity" associated with the megaprojects. The paper by Barrarini on concept of project complexity is one the earliest papers, which reviews literature on project complexity in the context of project management [28]. The paper reviewed different definitions of complexity and proposed the definition as "consisting of many varied interrelated parts". Further, complexities were categorized as organizational and technological. The organizational complexity refers to depth of organizational hierarchical structure (vertical differentiation) and number of formal organizational units - departments and groups, and the division of tasks (horizontal differentiation). The technological complexity refers to variety or diversity of some aspect of a task and interdependencies between tasks, teams, technologies and inputs.

Brockmann \& Grimscheild defined complexity as the degree of manifoldness, interrelatedness and consequential impact of a decision field. Overall project complexity comprises three components: task (density of activities in a spatial and temporal frame), social (number and diversity of actors) and cultural complexity (diversity of the cultural software of the mind) [2]. Bosch-Rekveldthig highlighted the lack of an accepted 
framework to understand project complexity in the context of a large engineering project [30]. A technical, organizational and environmental framework was proposed, which addresses this gap. Some of the elements related to these complexities are as follows: technical - number of goals, goal alignment, clarity of goals, scope; organizational- project duration, size of project team / site area, resources and skills availability, financial resources; environmental: variety of stakeholders perspectives, political influence and weather conditions.

He et al (2015) developed a complexity measurement model comprising six categories technological, organizational, goal, environmental, cultural and information complexities [32]. Some of the sub factors under these categories are as follows: 1) Technological diversity of technology, interdependence between the technological system and the external environment. 2) Organizational complexity: number of organizational structure hierarchies and organizational units / departments, 3) goal complexity: uncertainty of goals, uncertainty of project, diversity of task, 4) Environmental complexity: multiple stakeholders, environment of changing economy, environment of changing nature, 5) cultural complexity: multiple participating countries, project team's trust, sense of cooperation, cultural differences, and 6) Information complexity: information uncertainty, level of processing information, capacity of transferring information and integration of more than one system or platform. Along the lines of Hu et al (2015), another study by Lu et al (2015) reviewed the literature on types of complexity and proposed a Task - Organizational (TO) complexity framework for measurement of complexity of large scale projects $[9,32]$. The task complexity factors include amount of task, pooled / sequential and reciprocal interdependence while organizational complexity factors includes amount of organizational members, degree of centralization / formalization and matrixing.

\section{Research methodology}

This research study follows a qualitative research strategy, which is appropriate if the research question / problem at hand is exploratory in nature. Content analysis is a qualitative research strategy that involves interpreting and coding textual material for making replicable and valid inferences. The process includes evaluation of texts such as documents, oral communication and graphics and conversion of qualitative data into quantitative data. Hesigh (1988) discussed three types of content analysis: conventional, directed and summative [22]. The procedure followed for generation of initial codes has been proposed as a key differentiating parameter among conventional, directed and summative approaches to content analysis. The codes/keywords are derived from data and theory or relevant research findings in conventional and directed content analysis, respectively, while in case of summative content analysis, it is derived from interest of researchers or review of literature.

The types of content analysis are described based on the process of analysis- inductive or deductive way. The inductive approach is adopted when there is insufficient knowledge about the phenomenon or knowledge is fragmented. On the other hand, deductive content analysis is formed on the basis of previous knowledge with the purpose of theory testing. The inductive data moves from specific to general and deductive approach moves from the general to specific, being based on earlier theory / model [25].

In the first stage, we have used summative content analysis and inductive approach as described by Hesigh 1988 and Elo \& Kyngas 2007, respectively, which is followed by deductive content analysis as mentioned by Elo \& Kyngas 2007 in the second stage [2225]. We have used the NVIVO 11 software for the content analysis. The use of this software allows for analytical flexibility and enhances transparency and trustworthiness of the qualitative research process. 
In the first step, we have used word frequency query in the NVIVO software, to know the number of times a particular word has been repeated in the flash reports on megaprojects published by MoSPI. Cluster analysis has been carried out in the second step to identify words falling under a specific node and Pearson's correlation has been performed between the nodes for the same word.

\section{Analysis}

\subsection{Word frequency query}

We have manually searched various progress reports on megaprojects published by the MoSPI. Although the $1{ }^{\text {st }}$ megaproject report was published in June 2009, the earliest report available on the website of the MoSPI is January 2012. Since then, reports have been published on a monthly basis. However, a few reports are not available in the database of MoSPI. After going through the available reports, we have shortlisted 22 reports that have reported on the reasons for delays in megaprojects. These 22 reports comprise $2,12,8$ reports published in the years 2014, 2015 and 2016, respectively. We have separated the part of this report indicating reasons for delay for specific megaprojects.

We have uploaded these reports in NVIVO software and run word frequency query for identifying top 100 reasons based on frequency of occurrences in these reports. The word query has multiple options in selecting exact match, stemmed words, synonymous words and generic words. We have referred the reasons reported and observed synonymous words are often used for reporting delays in megaprojects. Therefore, we have selected the best fit option - synonyms, which eliminate the same intent appearing again and again in different words. Many irrelevant words such as page no, year of project conceptualization, approval and so on, present in the report, were added in the stop word list of software, to avoid them from appearing in the maximum times in word frequencies. Table 1 shows the list of top 20 words related to the reasons causing delay in the megaprojects. The output of word frequency query indicates the count and length of word, and similar words that are counted under particular parent word.

Table 1. Word frequency for reasons behind delay in megaprojects.

\begin{tabular}{|c|l|r|r|l|}
\hline $\begin{array}{c}\text { Sr } \\
\text { no }\end{array}$ & \multicolumn{1}{|c|}{ Word } & Length & \multicolumn{1}{c|}{ Count } & \multicolumn{1}{|c|}{ Similar words } \\
\hline 1 & Land & 4 & 408 & acres, country, land, lands, shore, soil \\
\hline 2 & Clearance & 9 & 276 & clearance, clearances \\
\hline 3 & Fund & 4 & 104 & fund, funds \\
\hline 4 & Performance & 11 & 96 & $\begin{array}{l}\text { act, operation, operational, operations, } \\
\text { performance }\end{array}$ \\
\hline 5 & Contractual & 11 & 76 & contractual \\
\hline 6 & Law & 3 & 66 & law, legal, right \\
\hline 7 & Availability & 12 & 61 & access, availability, available, services \\
\hline 8 & Stoppage & 8 & 61 & closure, stay, stoppage, stopped \\
\hline 9 & Mine & 4 & 51 & excavation, mine, mines, mining \\
\hline 10 & Renewal & 7 & 50 & rehabilitation, renewal, revival, revived \\
\hline 11 & Equipment & 9 & 49 & equipment, equipment \\
\hline 12 & Villagers & 9 & 44 & settlement, village, villagers \\
\hline 13 & Rain & 4 & 43 & rain, rainfall, rains \\
\hline 14 & Up-gradation & 11 & 40 & elevated, rising, up-gradation \\
\hline 15 & Change & 6 & 39 & $\begin{array}{l}\text { change, changed, changes, modification, } \\
\text { shifted, switch }\end{array}$ \\
\hline 16 & Compensation & 12 & 37 & compensation, repair, repairing, right \\
\hline
\end{tabular}




\begin{tabular}{|l|l|r|r|l|}
\hline 17 & Manpower & 8 & 37 & manpower, workforce \\
\hline 18 & Tender & 6 & 35 & raw, tender, tendered, tendering, tenders \\
\hline 19 & Geology & 7 & 28 & geological, geology \\
\hline 20 & Mobilization & 12 & 28 & mobilization, mobilize \\
\hline
\end{tabular}

'Land 'emerged as most frequently appearing word in the reasons behind delays in megaprojects. The construction of megaprojects often requires acquisition of large tracks of land in road, port, power and airport sector. This results in opposition of land owners to the megaprojects owing to fears of compromised livelihood opportunities, displacements, insufficient compensation and disruption in social fabric. The megaproject implementing agencies have been facing challenge in addressing concerns of these land owners in the framework of megaproject execution [12].

'Clearance 'was the second most frequently appearing word. The timely and speedy environmental and forest clearance has remained the bone of contestation among the approval agencies, infrastructure developers and implementing agencies [20]. The delays in clearance has led to huge time and cost overruns, and even the abandonment of projects by infrastructure developers in some cases [16]. The Central government has initiated some steps like enactment of Land Acquisition Law and release of guidelines for forest clearance to overcome hurdles in land acquisition as well as environmental and forest clearances $[20,26]$.

The word "performance" has referred in the context of poor/unsatisfactory performance of contractor in executing the megaprojects. The risks, complexities and uncertainties associated with megaprojects requires matching capabilities in the contractor responsible for executing the projects. As the megaprojects are becoming a popular procurement mechanism, there is a need for up scaling of capacities of contractors in areas such as project management, financial engineering, and technology adoption. In many instances, the contractors executing the megaprojects undermine the associated complexities and uncertainties at bidding phase and it results into hurdles in project implementation [12].

The creation of megaprojects involves utilization of enormous amount of financial resources and effective utilization / management of these resources poses a challenge in front of both - the implementing agencies and contractors. The time and cost overruns severely affect the financial health of megaprojects. The implementing agencies and the contractors have to infuse financial resources, which these stakeholders often lack or face difficulties in financial resource mobilization, for bringing the project on the track. "Fund", which is one of the frequently used word, reflects the scenario of financial distress faced by megaprojects. The implementing agencies are advised to closely monitor the progress of work, promptly resolve the bottlenecks and create financial buffer to tide over this situation.

The term "contractual" indicates that challenges faced by contracts in governing the risky and uncertain megaprojects. The construction contracts that lacks flexibility in dealing with emergent uncertainty and/or unexpected twists and turns in megaproject implementation creates hurdles. The contract designed for megaprojects should include front end mechanisms for enhancing ex-post governability and encourage collaborative and coordinated behaviour [21]. These mechanisms should be enshrined and supported by strong legal and institutional framework. This framework should provide public officials at the helm of decision making position in megaproject necessary comfort and confidence in dealing with the uncertainties. 


\subsection{Cluster analysis}

The second stage of this study involved cluster analysis performed with NVIVO software. This exploratory technique has been used for grouping sources or nodes based on similar words or attribute values in secondary data or coded similarly by nodes. Among these three types, this research study has used clustering by word similarity. We have first created four nodes namely: overruns, technical complexity, environmental complexity and organizational complexity. This is followed by applying node - overruns to the text containing the reasons for project delay, as mentioned in the reports. This is followed by selecting a specific reason for delay and applying particular complexity code. We have conceptualized the complexities as follows:

i) Task complexity, ii) Organizational complexity and iii) Environmental complexity.

Task complexity: Megaprojects consist of multiple tasks from various fields like engineering, technology, finance and organization management. It also includes ecological protection, energy saving and social stability [9]. These tasks are interconnected in many different ways and each task is affected by a change in other tasks and leads to a corresponding change in other tasks.

Organizationalcomplexity: This complexity focuses on the project team, members experience a number of hierarchies, size and organizational structure [9,27].

Environmental complexity: This complexity refers to where the megaproject operates, such as political, regulatory environment and market conditions [27]. The environmental complexity plays a vital increasing role because environment can impact the interest and needs of project stakeholders.

The similarity between each pair of words was measured by building a table with table columns - each different word that appears in the text of the sources and table cells number of times the column's word appears in the row's source. This is followed by calculation of a similarly index between each pair of items. We have calculated Pearson's correlation coefficient, which is shown in Table 2 below. This indicates strong correlation between overrun, and task and environmental complexity.

Table 2

\begin{tabular}{|l|l|r|c|}
\hline \multicolumn{1}{|c|}{ Nodes A } & Node B & Correlation coefficient $\mathbf{r}$ & Relation \\
\hline Task complexity factors & Overrun & 0.674 & Strong \\
\hline Organizational complexity factors & Overrun & 0.368 & Weak \\
\hline Environmental complexity factors & Overrun & 0.65 & Strong \\
\hline
\end{tabular}

\section{Conclusions}

Megaprojects have become a popular project delivery mechanism in India. The effectiveness of this mechanism hinges on understanding and overcoming hurdles faced in the execution of these projects. This work has qualitatively analysed the reasons behind delays in megaprojects implementation. Word frequency analysis lists delay in land acquisition and environmental clearances, weak capability of contractors, rigid contracting and legal structures and fund constraints as key reasons for delay in megaprojects. Cluster analysis shows the strong correlation between overruns and task and environmental complexity.

The findings of this research study can be used by decision makers to take appropriate steps towards overcoming theses hurdles.

As for limitations, this study is based on analysis of available reports of Indian megaprojects published by the MoSPI in the public realm. Free access to all reports can 
improve or refine the results of this study. Further, the reports indicate the reasons for delay in megaprojects. However, it does not distinguish between reasons causing time and cost overruns. Therefore, there is an inbuilt assumption that the reasons causing the delays may lead to both time and cost overruns. In practice, this may not hold true. Finally, the quality of reporting from different implementing agencies of megaprojects cannot be ascertained. This may lead to citing generic reasons for delay rather than exact causes.

\section{References}

1. Ahn, S., Asce, A. M., Shokri, S., Lee, S., Asce, M., Haas, C. TandAsce, F. J. Manage in Eng, Exploratory Study on the Effectiveness of Interface-Management Practices in Dealing with Project Complexity in Large-Scale Engineering and Construction Projects, 1-12, (2016).

2. Brockmann, C., Brezinski, H., \&Erbe, A.CIB World building Cong. Innovation in Construction Megaprojects, 1-9(2016).

3. Davies, T.B.A. Proj. Manag. J. The art of managing relationships in interorganizational collaboration. 7(3), 47-67 (2014).

4. Hu, Y., Chan, A. P. C., \&Le.J.of Management in Engineering, Understanding the Determinants of Program Organization for Construction Megaproject Success : Case Study of the Shanghai Expo Construction, 31(5)(2015).

5. Hu, Y., Chan, A. P. C., Le, Y., \& Jin, R. J. of Mange in Eng,From Construction Megaproject Management to Complex Project Management : Bibliographic Analysis, 1-11, (2015).

6. Implementation, P., Division, P. M., Bhavan, S. P., \& Marg, S. 82 nd REPORT ON MEGA PROJECTS ( Rs . 1000 Crore and above ) Government of India Ministry of Statistics and Programme Implementation Infrastructure and Project Monitoring Division, Report 82 (March, 2016).

7. Bent Flyvbjerg.The Oxford handbook of Megaproject management (2014).

8. LPomeranz, K. Asia Pacific J.The Great Himalayan Watershed: Water Shortages, Mega-Projects and Environmental Politics in China, India, and Southeast Asia. , 7(30), 1-27 (2009).

9. Lu, Y., Luo, L., Wang, H., Le, Y., \& Shi, Q.Int J. of Proj. Manag.Measurement model of project complexity for large-scale projects from task and organization perspective, 33(3), 610-622, (2015).

10. Vijaybaskar, M. \&Babu, S.M.Economic \& Political Weekly. The Politics of Urban Mega-projects in India. Income Employment Linkages in Chennai's IT Corridor,II(17), 85-92 (2016).

11. Rajan, T. A., Gopinath, G., \&Behera, M. Jour. of Const. Eng. \& Manage,PPPs and Project Overruns : Evidence from Road Projects in India, 140(2004), 1-10(2014).

12. V.S.K. \& Mahalingam, A. Engineering Proj.Orga. Conference.A Framework for Post Award Project Governance of Public-Private Partnerships in Infrastructure Projects, 1-22 (2013).

13. T Perveen, J.B.S. Economic \& Political Weekly.Interlinking of Rivers in India: Costs and Benefits, (Dec), 5307-5316 (2004).

14. Siemiatycki, M. Inter. J. of Urban and Regional Research. Message in a Metro: Building urban rail infrastructure and image in Delhi, India.30(2), 277-292 (2006).

15. Follmann, Alexander. Habitat Inter. Urban mega-projects for a 'world-class' riverfront - The interplay of informality, flexibility and exceptionality along the Yamuna in Delhi, India. 45(3), 213-222 (2015).

16. NHAI, Environment ministry spar over GMR project termination. 
17. Flyvbjerg, B., Bruzelius, N., and Rothengatter, W.Cambridge University Press, Cambridge, U.K, Megaprojects and risk: An anatomy of ambition, (2003)

18. Flyvbjerg, B. "What is a megaproject?" (May 19, 2011).

19. Flyvbjerg, B.Proj Manage J. "From Nobel Prize to project management: Getting risks right."37(3), 5-15 (2006).

20. Government of India. Ministry of Environment, Forest and Climate Change Government of India.

21. Sanderson, J.IJPM.Risk, uncertainty and governance in megaprojects: A critical discussion of alternative explanations.30(4), 432-443 (2012).

22. Helgevold, N. \& Moen, V. Nordic Journal of Digital Literacy. The use of flipped classrooms to stimulate students' participation in an academic course in initial teacher education.2015(1), pp.29-42 (2015).

23. Kaefer, F., Roper, J. \& Sinha, P. Kaefer Forum Qualitative Sozialforschung / Forum : Qualitative Social A Software-Assisted Qualitative Content Analysis of News Articles: Example and Reflections Kaefer2 . Literature Review. 16(2), 1-16 (2017).

24. Mayring, P. Forum Qualitative Sozialforschung / Forum : Qualitative Social 2 . History of Content Analysis 3. Basic Ideas of Content Analysis 4. Procedures of Qualitative Content Analysis, 1(2), pp.1-7 (2014).

25. Elo. Satu and HelviKyngas. Journal of Advanced Nursing. The qualitative content analysis process. 62(1), 107-115 (2008).

26. Raghuram; Samantha \& Satyam Shivam. Brunn S, Engineering.Mega projects in India Environmental and Land Acquisition Issues in the Road Sector,(2009).

27. Bosch-Rekveldt, M. et al.IJPM, Grasping project complexity in large engineering projects: The TOE (Technical, Organizational and Environmental) framework, 29(6), 728-739 (2011).

28. Baccarini, D. IJPM,The concept of project complexity - a review, 14(4), 201-204 (1996).

29. Williams, T.M.IJPM.The need for new paradigms for complex projects, 17(5), pp.269273 (1999).

30. Bosch-Rekveldt, M. et al.IJPM,Grasping project complexity in large engineering projects: The TOE (Technical, Organizational and Environmental) framework, 29(6), pp.728-739 (2011).

31. Williams, G.M.J. IJO\&PM. Now, let's make it really comlex (complicated). A systematic review of the complexities of projects,31(9), pp.966-990 (2011).

32. He, Q. et al.IJPM,Measuring the complexity of mega construction projects in China-A fuzzy analytic network process analysis, 33(3), pp.549-563 (2015).

33. Pomeranz, K. The Asia Pacific Journal.The Great Himalayan Watershed: Water Shortages, Mega-Projects and Environmental Politics in China, India and Southeast Asia.7(30), pp.1-27(2009). 